\title{
The Impact of Taxation Policies on the Performance of Small to Medium Enterprises
}

Submitted 21/05/21, 1st revision 22/06/21, 2nd revision 30/07/21, accepted 20/08/21

\author{
Wadesango Ongayi ${ }^{1}$, Doctrine Tadiwanashe Muzenda ${ }^{2}$, \\ Jonathan T Satande ${ }^{3}$, Khashane S Malatji ${ }^{4}$
}

\begin{abstract}
:
Purpose: The study investigates challenges faced by Small and Medium Enterprises (SMEs) in the introduction of new government taxation policies to financial performance of SMEs.

Design/Methodology/Approach: Multiple regression model were used to measure the relationship between point of sale transaction tax, mobile money taxes and financial performance. SPSS and EXCEL were used to analyze the study data and to identify the descriptive characteristics of the dependent and independent variables and results of the test.

Findings: From the research conducted the research findings indicate that intermediate money tax transfer has a significant impact on the financial performance of SMEs, the research also showed that there is a negative impact of mobile money tax transfer and bank transfer tax to the financial performance of SMEs. It was also established that there is a negative relationship between SMEs in the supply chain as all SMESs agree that mobile electronic tax transfer result in increase in cost of transactions and decrease in number of transactions.

Practical Implications: Consultations between government, stakeholders and revenue authority should be encouraged so as to accommodate SMEs when introducing new taxation policies. Policy makers should consider tax reduction and increase tax incentives to SMEs in order to boost their financial performance. While both consumers and SMEs have very genuine reasons to strongly agree that IMTT has increased their cost of transactions and resulted in decrease in purchasing power, the government should refine the legislation from an administrative point of view and also relook at it so as to lessen the burden on the final consumer and decrease the cost of doing business.
\end{abstract}

Originality/Value: It considers the fact that the intermediate tax has impact on the economy and small businesses.

Keywords: SMEs, taxation policies, purchasing power, revenue authority, tax transfer.

JEL codes: $C 1, C 4, C 5$.

Paper type: Research article.

\footnotetext{
${ }^{1}$ Dr., University of Limpopo, South Africa: ongayi.wadesango@ul.ac.za

${ }^{2}$ Midlands State University, Zimbabwe: dmuzenda@msu.ac.zw

${ }^{3}$ Midlands State University, Zimbabwe: jtsatande@gmail.com

${ }^{4}$ Dr., Tshwane University of Technology:MalatjiKS@ tut.ac.za
} 


\section{Introduction}

The aim of this research was to assess the effects of changes in government policies on small to medium enterprises (SMEs) in Zimbabwe. The study looked into how certain changes in government policies especially changes in taxation policies affect the performance of small businesses. The study was based on the period between 2016 and 2019 which are majorly characterized with introduction of new policies.

\section{The Background of the Study}

Alabi, David, and Aderinton (2019) asserted that in today's world small and medium scale enterprises (SMEs) is one of the most authentic drivers of sustainable development, especially in the emerging economies. This view was also shared by other Indian based researchers namely Raravi and Timnagoudar (2014) who stated that SMEs are vital and of paramount importance to countries especially for developing country like India.

Taxation is a charge levied on citizens and companies. Tee, Baadi, and Opoka (2016) define tax as an obligating payment which the country imposes on its citizens, firms and organizations not as penalty for offence or immediate exchange of goods but as income to enable government to meet its expenditures. Revenue generated from taxation is used by the government to meet its expenditures and cater for the needs of the public. Government charges various taxes in order to generate revenue. Some of the tax systems found in Zimbabwe are cooperate tax, value added $\operatorname{tax}$ (VAT) and pay as you earn (PAYE). Njanike (2019) states that the challenges faced by small businesses has caused them not to grow that is low profitability and depressed growth. The research seeks to find the impact of government taxation policies on the performance of SMEs.

Taxation has become one of the major causes of poor performance of SMEs. Chude and Chude (2015) pointed out that taxation had significant impact on cooperate profitability. William (2017) also agrees that taxation policy is one of the government policies that affect businesses directly because taxation is based on the amount earned by businesses. However, Ibrahim and Muritala (2015) state that businesses can pass some of this tax on to consumers in high prices but it will affect the bottom line. On the other hand, Irongwe and Peter (2015) argue that value added tax (VAT) has no direct bearing on cooperate financial performance since the burden is simply passed.

\section{The Research Model}

Mbah and Obiezekweh (2018) in the research electronic banking and performance of SMEs in Nigeria used a multiple regression analysis to evaluate the relationship between electronic banking and performance of SMEs. The relationship between 
point of sale transaction tax, mobile money taxes and financial performance is measured using the following multiple regression model:

$$
\mathrm{S}=\beta+\beta_{1} M M_{1}+\beta_{2} P_{2}+\beta_{3} B T_{3}+\varepsilon
$$

Where:

$\mathrm{S}-$ Sales revenue

$\beta$ - Constant

MM- Mobile money transfer tax

$\beta_{1} / \beta_{2}$-are parameters

POS- point of sale transfer tax

BT- bank transfer

e- Error term.

SPSS and EXCEL were used to analyze the study data and to identify the descriptive characteristics of the dependent and independent study variables and results of the test.

\section{Research Results}

\subsection{Multiple Regression Analysis}

According to Mbugua and Maronge (2016) R squared shows the proportion in the dependent variable that can be explained by independent variable in the study $\mathrm{R}$ square was 0,874 which show that the three dependent variable which are mobile money, point of sale and bank transfer explain most of the dependent variable which is financial performance of small to medium enterprises in Gweru CBD at $87.5 \%$. This shows that the other factors not considered into the study explain the least of the dependent variable at $12.5 \%$.

Table 1. Analysis of Variance

\begin{tabular}{lllllc}
\hline & $D f$ & $S S$ & $M S$ & $F$ & Significance $F$ \\
\hline Regression & 3 & 9.362 & 3.120 & 12.307 & 0000 \\
Residual & 164 & 13.528 & 0.119 & & \\
Total & 167 & 22.89 & & & \\
\hline
\end{tabular}

Source: Own study.

The analysis of variance in this study was used to determine whether the regression model is a good fit for the data. The results show that the model was significant since the p-value is 0.000 which is less than 0.05 thus the model is statistically significance in predicting the influence of the three independent. According to Westfall (2020) States that a predictor that is low p-value is likely to be meaningful addition to a model which is $(<0.05)$. Further the F-calculated $(12.307)$ was more than F- critical (2.4472) which shows that the model was fruitful in predicating the influence of independent variables on the dependent variable. 
Table 2. Regression coefficients

\begin{tabular}{llllll} 
& B & Std. Error & Beta & & \\
\cline { 3 - 6 } (Constant) & 8.14 & 0.193 & & 4.218 & .000 \\
Point of sale (swipe) & 1.56 & 0.095 & -0.194 & -1.639 & .000 \\
Mobile money & -0.293 & 0.054 & -0.302 & -0.543 & .000 \\
Bank transfer & -0.508 & .087 & -0.397 & -0.578 & .000
\end{tabular}

Source: Own study.

The constant term $\beta$ shows that when the four independent variables are held constant the financial performance of SMEs in Gweru CBD will be 8.14. The research showed that mobile money tax transfer inversely and significantly influences the performance of SMEs in Gweru CBD ( $\beta=0.293 \mathrm{P}$ - value $=000)$. This shows that a unit increase in mobile money tax transfer will result in decrease in financial performance of SME in Gweru CBD. Since the P-value is (000) is less than (0.05) there is an inverse relationship between mobile money tax transfer and the financial performance of SMEs in Gweru district. The finding also shows that Bank transfer tax inversely and significantly influences the performance of SMEs in Gweru CBD $(\beta=0.508$ P- value =000). This shows that a unit increase in bank transfer tax will result in decrease in financial performance of SME in Gweru CBD. Since the P-value is $(000)$ is less than $(0.05)$ there is an inverse relationship between bank transfer tax and the financial performance of SMEs in Gweru district.

According to the findings there is a positive relationship between point of sale and the financial performance of small to medium enterprises in Gweru CBD $(\beta=1.56 \mathrm{P}$ value $=000)$. This shows that a unit increase in point of sale tax will result in increase in financial performance of SME in Gweru CBD. Since the P- value is (000) is less than (0.05) therefore we can conclude that there is a positive relationship between point of sale transfer tax and the financial performance of SMEs in Gweru district. The study reviewed that taxation lowers the business financial performance. In agreement Tee, Boadi and Opoku (2016) agreed to this in their research on the effects of tax payment on the performance of SMEs by pointing out that taxation has a significant effect on the performance of small to medium enterprises. The respondents also indicated the businesses are weakened due to the increase in tax rate hence poor performance of businesses.

\subsection{Major Findings}

The first objective was sought to examine the impact of intermediate money tax transfer to the financial performance of SMEs. The electronic transfers assessed in this research are mobile money tax transfer, point of sale and bank transfer. It was discovered that mobile money tax transfer inversely and significantly influences the performance of SMEs in Gweru CBD $(\beta=0.293 \mathrm{P}$ - value $=000)$. This shows that a unit increase in mobile money tax transfer will result in 0.293 decrease in financial performance of SME in Gweru CBD. The finding also shows that Bank transfer tax 
inversely and significantly influences the performance of SMEs in Gweru CBD $(\beta=0.508 \mathrm{P}$ - value $=000)$. This shows that a unit increase in bank transfer tax will result in decrease in financial performance of SME in Gweru CBD. According to the findings there is a positive relationship between point of sale and the financial performance of small to medium enterprises in Gweru CBD $(\beta=1.56 \mathrm{P}$ - value $=$ 000). This shows that a unit increase in point of sale tax will result in increase in financial performance of SME in Gweru CBD.

The second objective was sought to determine the impact of mobile money tax transfer to the financial performance of SMES. The results showed an increase in cost of transactions, decrease in number of transactions, loss of customers and lastly decrease in purchasing power. The results also showed that an aggregate of $95.83 \%$ of mobile money users agree that there was an increase in cost of transaction and the remaining percentage being neutral (4.16) on the issues of increase in cost of transaction ever since the introduction of IMTT.

The researchers also discovered that an aggregate of $75 \%$ of mobile money users agree that mobile money tax transfer resulted in increase in decrease in number of transactions, $12.5 \%$ were not in agreement and a percentage of 14.58 were neutral. SMEs that accept mobile money as mode of payment $41.66 \%$ of the firms in Gweru CBD agreed that the taxation policy resulted in loss of consumers, however $33.33 \%$ where neutral and a total of $25 \%$ disagreed that IMTT on mobile money resulted in loss of consumers. It was also found out that an aggregate of $60.42 \%$ of mobile money users agreed that the taxation policy have resulted in decrease in purchasing power while $37.5 \%$ where neutral on the issue and $2.08 \%$ in total disagreed that it resulted in decrease in purchasing power.

The third objective was sought to determine the impact of point of sale tax transfer to the financial performance of SMES. The results show a summary of the following impact which are increase in cost of transactions, decrease in number of transactions, loss of customers and lastly decrease in purchasing power. The results also showed that an aggregate of $92.11 \%$ of POS users agree that there was an increase in cost of transaction and the remaining percentage being neutral (7.89) on the issues of increase in cost of transaction ever since the introduction of IMTT.

The researchers also discovered that an aggregate of $68.42 \%$ of POS users agree that point of sale tax transfer resulted in increase in decrease in number of transactions, $18.42 \%$ where not in agreement and a percentage of $13.56 \%$ where neutral.

SMEs that accept point of sale as mode of payment $26.32 \%$ of the firms in Gweru CBD agreed that the taxation policy resulted in loss of consumers, however $47.36 \%$ where neutral and a total of $26.32 \%$ disagreed that IMTT on point of sale resulted in loss of consumers. It was also found that an aggregate of $39.47 \%$ of POS users agreed that the taxation policy have resulted in decrease in purchasing power while 
$50 \%$ where neutral on the issue and $10.52 \%$ in total disagreed that it resulted in decrease in purchasing power.

The fourth objective was sought to determine the impact of bank tax transfer to the financial performance of SMES. The results show a summary of the following impact which are increase in cost of transactions, decrease in number of transactions, loss of customers and lastly decrease in purchasing power. The results also showed that an aggregate of $88.87 \%$ bank transfer users agree that there was an increase in cost of transaction and the remaining percentage being neutral (16.13) on the issues of increase in cost of transaction ever since the introduction of IMTT.

The researchers also discovered that an aggregate of $58.06 \%$ of bank transfer users agree that bank tax transfer resulted in decrease in number of transactions, $22.58 \%$ where not in agreement and a percentage of $16.13 \%$ where neutral.

SMEs that accept bank transfers as mode of payment $12.90 \%$ of the firms in Gweru CBD agreed that the taxation policy resulted in loss of consumers, however $38.71 \%$ where neutral and a total of $9.78 \%$ disagreed that IMTT on bank transfer resulted in loss of consumers. It was also found out that an aggregate of $32.58 \%$ of bank transfer users agreed that the taxation policy have resulted in decrease in purchasing power while $54.84 \%$ where neutral on the issue and $12.90 \%$ in total disagreed that it resulted in decrease in purchasing power.

The last objective was sought to find the relationship between SMEs in the supply chain. It was found that there is a negative relationship between SMEs in the supply chain as all SMESs agree that mobile electronic tax transfer result in increase in cost of transactions and decrease in number of transactions. The results also showed that consumer agree that IMTT has resulted in increase in cost of transactions and also decrease in their purchasing power.

\section{Conclusion}

The study concludes that taxation lowers business financial performance and also that taxation has a significant effect on the performance of SMEs. An increase in mobile money tax transfer and bank transfer tax will result in a decrease in financial performance of SMEs. This showed that IMTT has a significant effect on the financial [performance of SMEs.

However, Point of sale transfer tax positively affect the financial performance of SMEs. This is true because the results showed that an increase in IMTT results in an increase in cost of transaction in every business sector in the supply chain therefore resulting in a decrease in purchasing power reducing the number of sales volume and as a result affecting the consumers' buying behavior. There is also a compounded effect on the financial performance of SMEs. 


\section{References:}

Adegoke, Y. 2019. More African Countries Are Looking To Tax Mobile Money [online] Available at: https://www.uncdf,org/article/3892/understanding-the-consequencesof-mobile-money-taxes-in-Uganda.

Adejare, A.T. 2015. The Analysis of the Effect of Corporate Income Tax (CIT) on Revenue Profile in Nigeria. American Journal of Economics, Finance and Management, 1(4), 312-319.

Alabi, J., David, F., Aderinton, N. 2019. The Impact of Government Policies on Business Growth of SMEs in South Western Nigeria. International Journal Management Studies and Social Science Research, 2, 34-43.

Bhati, K. 2019. Reflection: Research by design: Design based research and the higher degree research student. Journal of Learning Design, 6(2), 76-87.

Bhakta, P. 2016. Budget 2016: Swiping your cards may help you save tax [online]. Available at: https//www.m-economictimes.com/news.

Chude, P.I., Chude, P. 2015. Impact of Company Income Taxation on the Profitability of Companies in Nigeria: A study of Nigeria Bravery. European Journal of Accounting, Auditing and Finance Research, 3(8), 1-11.

Debois, S. 2019. Advantages and Disadvantages of Questionnaires [online]. Available at: http://suveryplace.com/questionaire-pros-snd-cons/.

Eniola, A.A., Entebang H. 2015. Government Policy and Performance of Small and Medium Business Management. International journal of Business and Development, 5(1), 117.

Ferracuti, A. 2018. Understanding The Consequences of Mobile Money Taxes in Uganda, [online]. Available at: https://tq.com/africa/1685571/africas-financial-inclusion-atrisk-from-mobile-money-taxes.

Ibrahim, T.M., Muritala, A.T. 2015. Does government Policies Improves Business Performance? Evidence from Nigeria. Journal of studies in Social Sciences, 11(2), 1-7.

Irokwe, U., Peter, T. 2015. Value Added Tax and Financial Performance of Quoted Agribusiness in Nigeria. International Journal of Business and Economic Development, 3(1), 79-86.

Mbah, S., Obiezekwem, J. 2018. Electronic Banking and Performance of SMES in Anabra State in Nighera, [online]. Available at: https://researchgate.com/electronic-bankingperformance-of-SMEs/125.

Miller, C. 2020. The Impact of Financial Inclusion Tax, [online]. Available at: https://taxfoundation.org/transaction-tax/.

Munjeyi, E. 2017. The Impact of Legal and Regulatory Framework on SMEs Development: Evidence from Zimbabwe. International Journal of Academic Research in Business and Social Sciences. 8(20), 57-105.

Nafula, T., Munu, M., Shinyekwa, I. 2018. How will recent taxes on mobile money affect east Africa, [online]. Available at: http://www.eprcug.org/blog/631-how-willrecent-taxes-on-mobile-money-affect-East-Africa.

Naisanga, P. 2019. Drop 0.05\% Tax On Mobile Money Tax [online]. Available at: https://ww.newvision.co.ag >new_vision>News >drop-0.5-mobile-money-tax.

Ocheni, S.I. 2015. Effects of Multiple Taxation on Financial Performance of Small to Medium Enterprises in Benue State. International journal of academic research in business and social sciences, 1(44), 312-319.

Raravi, P., Timmanagudar, S. 2018. Study on Government Policy and Regulatory Factors 
Which Are Affecting the Performance of SMEs (Manufacturing). Journal of studies in Social Sciences, 10(7), 25-36.

Sitharam, S., Hoque, M. 2016. Factors Affecting the Performance of Small and Medium Enterprises in Kwazulu Natal, South Africa. Journal of Studies in Social Sciences, 9(2), 36-50.

Tenday, T. 2019. The Inadvertent rise of digital transaction in Zimbabwe, [online]. Available at:

https://www.dlapiper.com/en/belgium/insights/puplications/2019/04/africaconnected-issue- 2 .

Tee, E., Boadi, L., Opoku, R.T. 2016. The effect of tax payment on the performance of SMEs: The Case of Selected SMEs. In: Ga West Municipal Assembly on Profitability of the Business. European journal business and management, 8(20), 318-320. 